\title{
Postharvest Browning of Rambutan is a Consequence of Water Loss
}

\author{
Margaret Landrigan ${ }^{1}$ \\ Northern Territory Department of Primary Industry and Fisheries, Berrimah, Australia \\ Stephen C. Morris \\ Commonwealth Scientific and Industrial Research Organisation, Division of Horticulture, Australia
}

Barry W. McGlasson

University of Western Sydney, School of Horticulture, Hawkesbury, Australia

Additional index words. color, desiccation, Nephelium lappaceum, relative humidity, storage, weight loss

\begin{abstract}
Rambutan (Nephelium lappaceum L.) rapidly lose their attractive appearance after harvest due to a superficial pericarp browning. Storage at high humidity minimizes fruit desiccation and may, therefore, delay browning onset. This paper examines the effect of reduced water loss rate on browning that may occur with time. Rambutan fruit pericarp browning beyond a commercially saleable level occurred at a weight loss of $25 \%$ to $40 \%$. This depended on duration and storage relative humidity (RH). Skin browning was $50 \%$ greater on the red (R 134) than the yellow (R 156) cultivar at $60 \%$ RH. There was a storage time $\times$ RH interaction in the development of browning such that browning was observed earlier at lower RHs. Skin browning and spintern (soft spine) browning developed independently. Cracks appeared on the surface of fruit with increased weight loss. Browning occurrence was consistent with increased total phenolic compound levels in the pericarp. Water loss precedes browning occurrence and, over time, water loss is related to browning. Water stress appeared to affect rambutan pericarp tissue in much the same manner as senescence.
\end{abstract}

Browning of rambutan after harvest has been attributed to skin desiccation (Mendoza et al., 1972; Pantastico et al., 1975; Wells and Bagshaw, 1989) and is highly correlated with weight loss, as a measure of water loss. Wells and Bagshaw (1989) found that high $(95 \%)$ relative humidity $(\mathrm{RH})$ storage minimized fruit desiccation and may, therefore, delay browning onset. But to what extent reduced water loss rate can offset browning, especially when water loss is reduced to almost zero, is not known.

The structure of rambutan pericarp facilitates rapid water loss, particularly through the spinterns and associated vascular tissue and stomata (Landrigan et al., 1994; Pantastico et al., 1975). Changes in cuticular structure and gross morphology (e.g., cuticle cracking) may be associated with water loss and enhanced susceptibility to browning (Burton, 1982). Mendoza et al. (1972), without supporting evidence, stated that moisture is lost mainly through spinterns. Furthermore, water loss has been reported to be highly correlated with browning (Lam et al., 1987). Unfortunately, the browning index used by Lam et al. (1987) referred only to spinterns, while other published work referred only to a general browning of the whole surface when discussing rambutan appearance (Mendoza et al., 1972).

This paper reports on an investigation into the relationship between water loss in controlled RH environments and fruit browning. In this study, spintern browning and skin browning were considered separately to establish the relationship, if any, of each of these tissues to water loss. We also investigated changes in surface characteristics of rambutan fruit and the effect of the interaction between storage time and water loss rate on browning rate.

Received for publication 10 Oct. 1995. Accepted for publication 14 Feb. 1996. We thank TK Lim for advice and Ian Knuckey and Rik Buckworth for reading of the manuscript and discussion. Funding assistance from the Rural Industries Research and Development Corporation is gratefully acknowledged. The cost of publishing this paper was defrayed in part by the payment of page charges. Under postal regulations, this paper therefore must be hereby marked advertisement solely to indicate this fact.

${ }^{1}$ To whom reprint requests should be addressed: DPIF, P.O. Box 79, Berrimah NT 0828 Australia.

\section{Materials and Methods}

Fruit. Rambutan fruit, at the fully colored, commercially mature stage (red skinned cultivar R-134 and yellow skinned cultivar $\mathrm{R}-156)$, were obtained from Coastal Plains Research Station, near Darwin, Australia (lat. $12^{\circ} \mathrm{S}$, long. $130^{\circ} \mathrm{E}$ ).

Storage conditions. RH was maintained as described by ForbesSmith et al., (1989) in a controlled temperature room, set at $20^{\circ} \mathrm{C}$, with the following modifications. A constant pressure air supply was divided into two streams, one dried to about $35 \% \mathrm{RH}$, and the other humidified to $>95 \% \mathrm{RH}$. These streams were then recombined, via metering valves, to give the desired $\mathrm{RH}(60 \%, 70 \%$, $80 \%, 90 \%$, or $95 \%$ ) and flow rate. The $\mathrm{RH}$ of the air leaving the storage container was measured at a position midway between the top of the fruit samples and the exhaust port. An electrohygrometer sensor (model PCRC-55T; Phys-Chemical Research Corp., New York) connected to an AC wheatstone bridge (model K-3468; Dick Smith, Sydney) was used to measure RH. The RH sensor was calibrated within an appropriate humidity range using saturated salt solutions (Weast et al., 1983). A rotameter was used to maintain flow rate at $10 \mathrm{~L} \cdot \mathrm{min}^{-1}$.

Color assessment. In the first year, 120 red and yellow fruit each were harvested early in the morning and transported to the laboratory within $2 \mathrm{~h}$, and 12 fruit were stored in 10-L plastic drums, with two drums at each of the five RHs within the range $60 \%$ to $95 \%$ $( \pm 5 \%)$, and $20^{\circ} \mathrm{C}$. Four fruit were removed from each drum at 3 , 6 , and 9 days after harvest, and weight loss by each fruit was measured. Browning was assessed using subjective color scores (scale 1-5: 1 = no browning; 5 = fully browned). Skin browning was assessed separately to spintern browning. In the second year, work was confined to the red cultivar (R 134). Twenty-five fruit were placed in each drum at each of the same five RH treatments. Five fruit were removed from each drum at 5, 7, 9, 11, and 13 days after harvest. Weight loss and subjective browning scores were recorded. Additionally, changes in color were quantified using a color meter (Chromameter II; Minolta, Osaka, Japan), with an 8$\mathrm{mm}$ measuring head and D-65 (6504K) illuminant. The values $\mathrm{L}^{*}$ 
Relative Humidity $(\%)$

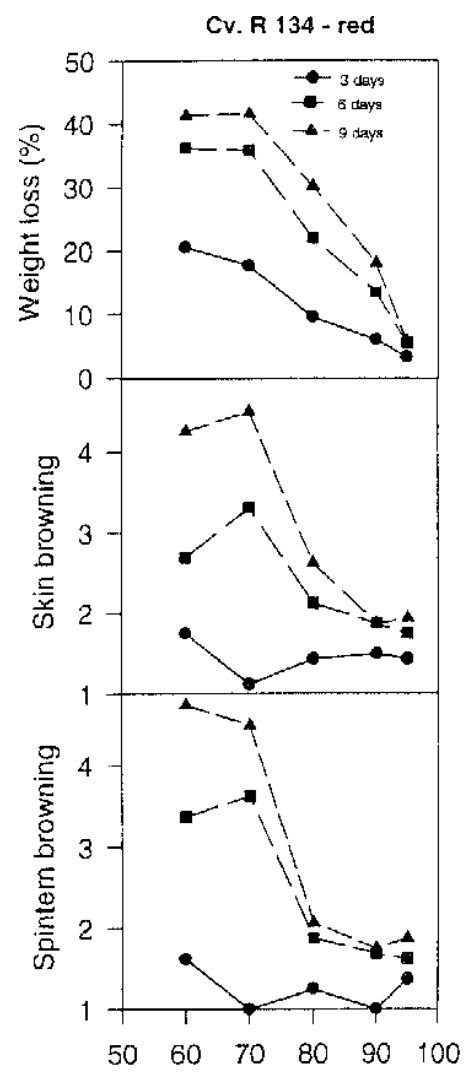

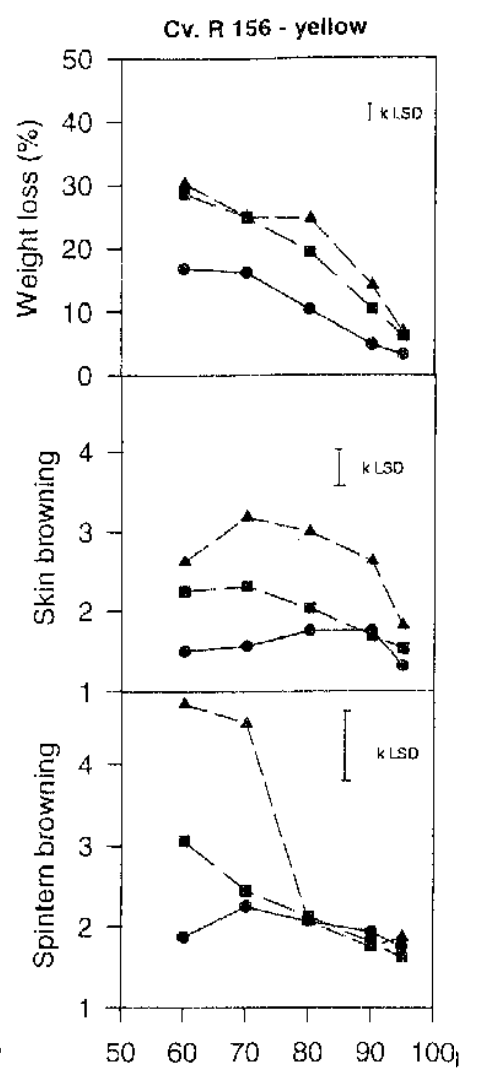

Relative Humidity (\%)
Fig. 1. The effect of relative humidity in storage on weight loss, skin and spintern' browning score $(1=$ no browning ; $5=$ fully brown $)$ in rambutan fruit (R 134 and $^{4}$ $\mathrm{R} 156$ ) in the 1991-92 season. Each point represents the mean of 8 fruit. The vertical bar represents the difference between the means using the kLSD ratio at $\mathrm{k}$ $=100$.

(lightness), $\mathrm{a}^{*}$ (redness), and $\mathrm{b}^{*}$ (yellowness) were recorded, and the color term total color difference $(\Delta \mathrm{E})$ was calculated from these values (Hung, 1990).

Total phenol determinations. Total phenol content of the skin was determined in the second year with a method adapted from $\mathrm{i}$ Rathjen and Robinson (1992). The skin was removed from five fruit and then frozen in liquid $\mathrm{N}_{2}$ and stored at $-20^{\circ} \mathrm{C}$ until needed. The samples were freeze-dried and pulverized using a coffee grinder. These powdered samples were returned to $-20{ }^{\circ} \mathrm{C}$ until required. Ten milligrams of tissue was weighed into a capped 1.5$\mathrm{mL}$ eppendorf tube, and $1 \mathrm{~mL}$ of $80 \%$ methanol was added and mixed thoroughly. This was left to stand at room temperature for $1 \mathrm{~h}$ and then centrifuged at $5,000 \times g$ for $10 \mathrm{~min}$. The supernatant was decanted and the pellet was resuspended with an additional 1 $\mathrm{mL}$ of $80 \%$ methanol. After centrifuging, the second supernatantwas combined and diluted with $80 \%$ methanol to $2 \mathrm{~mL}$ exactly by weight. Total phenols were measured using the Folin-Ciocalteau reagent (Singleton and Rossi, 1965) and a micromethod adapted from Rathjen and Robinson, (1992). Sample and water were mixed to a final volume of $800 \mu \mathrm{L}$, then $50 \mu \mathrm{L}$ of Folin-Ciocalteau reagent was added. The mixture was left for $2 \mathrm{~min}$ and then $150 \mu \mathrm{L}$ : of $20 \% \mathrm{Na}_{2} \mathrm{CO}_{3}$ was added and mixed thoroughly. Absorbance at $765^{\circ}$ $\mathrm{nm}$ was measured after $2 \mathrm{~h}$. This absorbance was calibrated against a standard curve of gallic acid at $5,10,15$, and $20 \mu \mathrm{g} \cdot \mathrm{mL}^{-1}$.

Scanning electron microscopy (SEM). SEM studies were made on epoxy resin replicas of rambutan fruit surface in the second year, following the method of Williams et al. (1987). Fruit surface morphology was observed by analyzing low magnification micrographs (about 500×) using a Jeol T330 SEM at $15 \mathrm{kV}$.

Statistical analyses. Data from all experiments were subjected to analyses of variance and, where appropriate, the means compared using Waller-Duncan's Bayesian k ratio LSD at k $=100$ (Steel and Torrie, 1980). The level of $\mathrm{k}=100$ used here is about equal to $P=0.05$ in conventional LSD. For the subjective color scores, the angular transformation was applied before analysis. Simple correlations between objective color values, subjective browning scores, and weight loss measurements were generated by linear regression analyses.

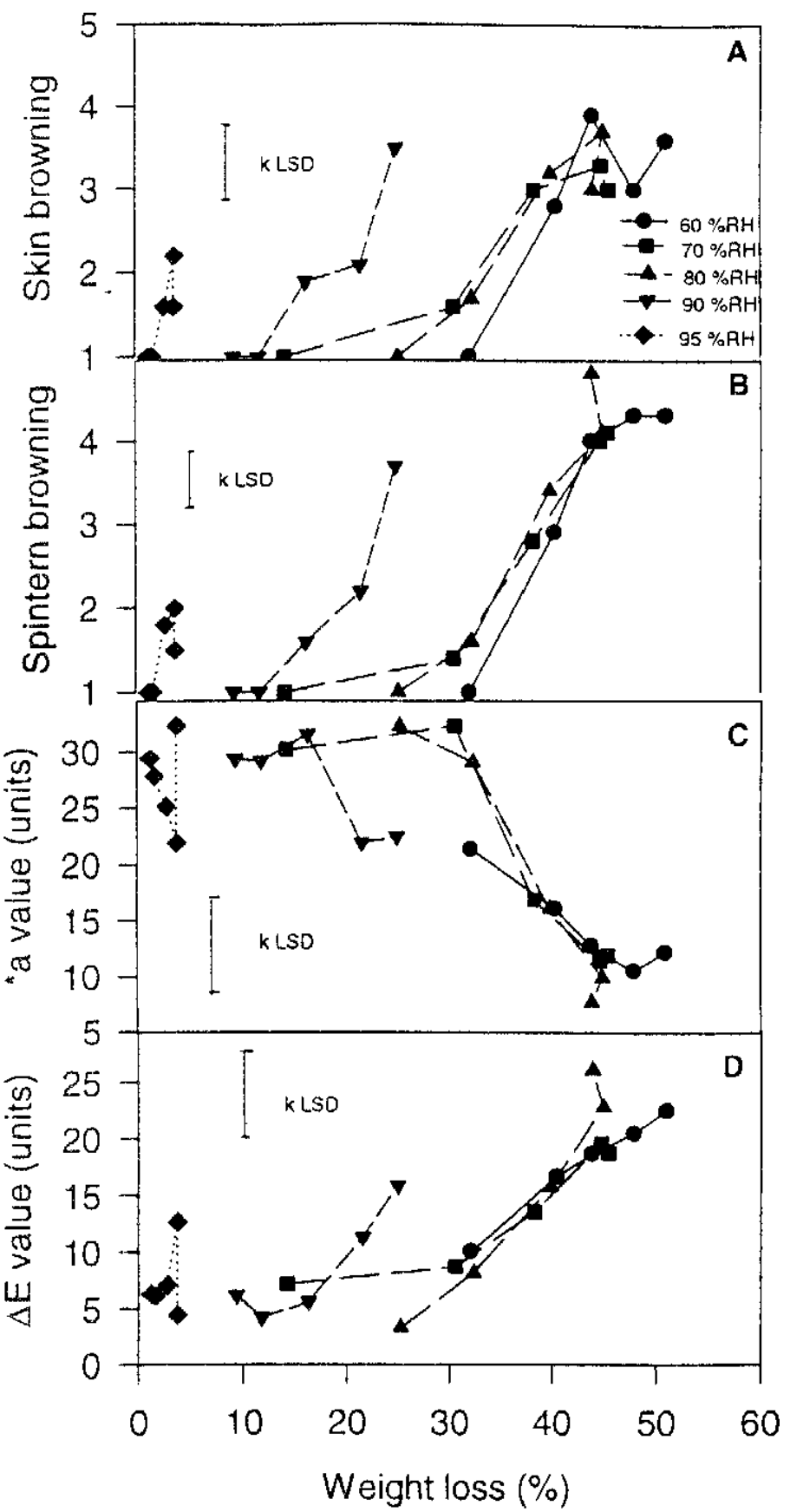

Fig. 2. Relationship of color parameters to weight loss in rambutan during storage in different relative humidities (1992-93 season). Each point represents the mean of five fruit for 5, 7, 9,11, and 13 days respectively (left to right). The vertical bar represents the difference between the means using the kLSD ratio at $\mathrm{k}=100$. 
Table 1. Correlation matrix for weight loss (Wt), browning of spinterns (Spin), and skin (Skin) and objective colour variables (L*, $a^{*}, b^{*}$, and $\left.\Delta \mathrm{E}\right)$ measured during storage at different RHs.

\begin{tabular}{|c|c|c|c|c|c|c|c|}
\hline & $\mathrm{Wt}$ & Spin & Skin & $\mathrm{L}^{*}$ & $a^{*}$ & $\mathrm{~b}^{*}$ & $\Delta \mathrm{E}$ \\
\hline$\overline{\mathrm{Wt}}$ & 1.000 & & & & & & \\
\hline Spin & $0.758^{*}$ & 1.000 & & & & & \\
\hline Skin & $0.679^{*}$ & $0.898^{* * *}$ & 1.000 & & & & \\
\hline $\mathrm{L}^{*}$ & -0.540 & $-0.648^{*}$ & -0.566 & 1.000 & & & \\
\hline$a^{*}$ & $-0.679^{*}$ & $-0.816^{*}$ & $-0.755^{*}$ & $0.656^{*}$ & 1.000 & & \\
\hline$b^{*}$ & -0.628 & $-0.683^{*}$ & -0.609 & $0.798^{*}$ & $0.751^{*}$ & 1.000 & \\
\hline$\Delta \mathrm{E}$ & $0.672 *$ & $0.830^{* *}$ & $0.753^{*}$ & $-0.684^{*}$ & $-0.862^{*}$ & $-0.759^{*}$ & 1.000 \\
\hline
\end{tabular}

\section{Results}

Weight loss rate in both cultivars was significantly reduced by increasing RH during storage (Fig. 1). Fruit lost weight progressively with time, and generally a greater percentage loss occurred during 3 to 6 days than 6 to 9 days for both cultivars (Fig. 1). The yellow cultivar (R-156) had a maximum weight loss of $30 \%$ at the lowest RH and a maximum weight loss of 6\% at the high RH (Fig. 1). Maximum weight loss was significantly higher in red fruit. Weight loss by the red cultivar (R-134) after 9 days at $60 \% \mathrm{RH}$ was $40 \%$, while after the same time at $95 \%$ RH it was only $6 \%$.

Skin browning increased with storage time, especially for $70 \%$ $\mathrm{RH}$ and below. Generally there was less browning in fruit stored at higher RH. The red cultivar had a lower skin browning score at day 3 of storage, with a higher skin browning score at the end of the storage period than the yellow cultivar. The scores for spintern browning followed trends similar to those for skin browning in the red cultivar. The only significant difference between the two cultivars for spintern browning scores, occurred at $80 \%$ RH after 9 days. The spintern browning scores for the yellow fruit were initially higher than those for the red fruit.

The relationship between skin browning and weight loss was complex (Fig. 2A). At 95\% RH, weight loss was minimal. Browning tended to increase with time, although browning levels remained commercially acceptable $(<2.5)$. At $90 \% \mathrm{RH}$, weight loss rate increased, with browning becoming commercially unacceptable ( $>2.5$ ) at day 13. For the three remaining storage RHs, weight loss and browning scores were similar, after day 5 . The same trends were apparent in the spintern browning patterns (Fig. 2B). The spintern browning scores, however, reached higher absolute levels over time for $\mathrm{RH}<90 \%$, indicating a more severe effect in this part of the fruit surface. The red intensity ( $\mathrm{a}^{*}$ values) of the fruit, declined at lower RH (Fig. 2C) and declined as percentage weight loss increased. Specifically, the a* values declined to 20 after $4 \%$ weight loss when fruit were stored at $95 \%$ RH but decreased to 20 after $20 \%$ to $40 \%$ weight loss if stored at lower RHs. Total color difference $(\Delta \mathrm{E})$ values increased as percentage weight loss increased (Fig. 2D), but the differences between RHs of $80 \%$ and less were the smallest of any parameter.

The best measurements for skin and spintern browning were $\Delta \mathrm{E}$ and $\mathrm{a}^{*}$, with $\Delta \mathrm{E}$ being the slightly better of the two. The higher degree of fit is indicated by the regression equation Spintern browning $=0.071+0.191 \Delta \mathrm{E}\left(r^{2}=0.915, P<0.01\right)$, suggesting that the color meter is useful to measure browning objectively. Weight loss was positively correlated with spintern and skin browning and $\Delta \mathrm{E}$ values (Table 1). Spintern browning was positively correlated with skin browning and $\Delta \mathrm{E}$ values and negatively correlated with $\mathrm{a}^{*}$ and $\mathrm{L}^{*}$ values, confirming loss of red color and lightness with browning (Table 1). Skin color, on the other hand, was not significantly correlate with the $\mathrm{L}^{*}$ values (Table 1 ).
The total phenol content of the skin was initially high, decreasing with time and increased browning and was lower for lower storage RHs than for high storage RHs (Fig. 3). These trends were correlated with spintern browning scores. Fruit stored at 95\% RH had minimal loss of total phenol content over the storage period while, after 5 days, total phenol content of fruit stored at $60 \% \mathrm{RH}$ was significantly lower and did not change with continued storage.

Rambutan pericarp stored at high RH (95\%) for 7 days showed epidermal cells on the spintern arranged in longitudinal columns resembling fibres that were turgid. On the skin, the epidermal cells were fully turgid without spaces. In contrast the pericarp, after 7 days storage at $60 \% \mathrm{RH}$, had cracks on the skin and spinterns. After 13 days, the cells at the surface of the fruit stored at $60 \% \mathrm{RH}$ were severely shrunken on the skin (Fig. 4A) more noticeably than for the spintern (Fig. 4B). Following shrinkage of the epidermal cells on the skin, crevices became apparent, while on the spintern the epidermal cells appeared to shrink and collapse and loose their column arrangement, leaving many intercolumnal spaces. By day 13 the surface of the fruit stored at 95\% RH only showed cracks without cellular collapse (Fig. $4 \mathrm{C}$ and D).

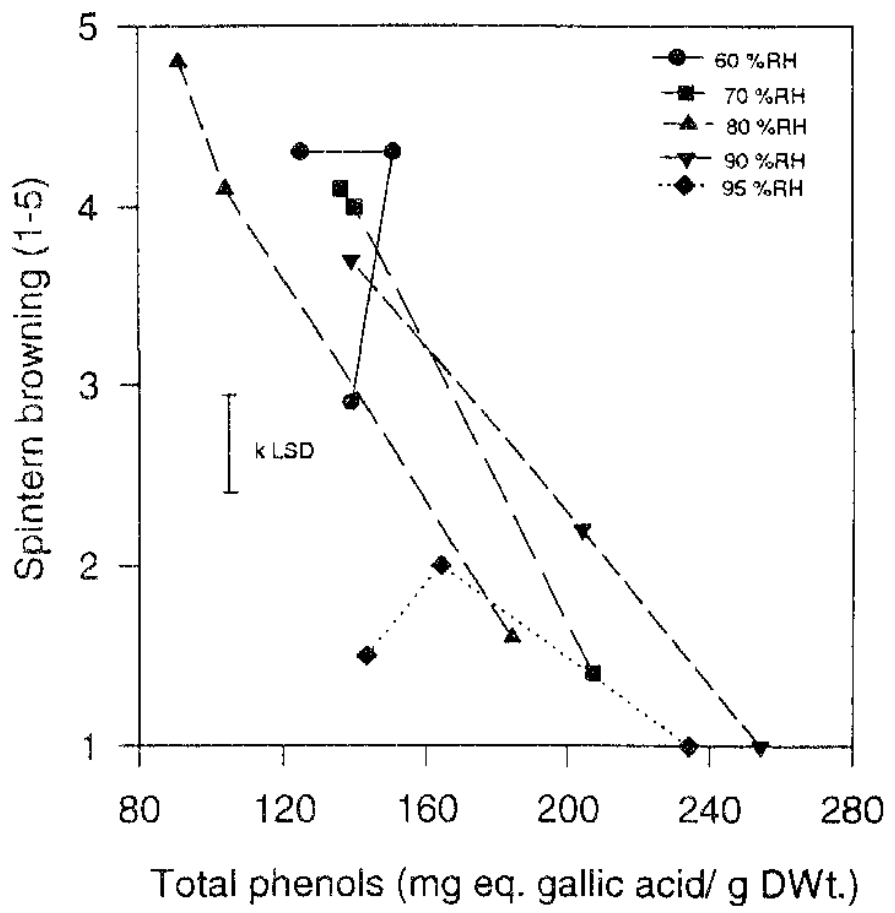

Fig. 3. Relationship between spintern browning ( $1=$ no browning; $5=$ fully brown $)$ and total phenols during postharvest storage at a range of relative humidities (1992-93 season). Each point represents the mean of five fruit for 5, 7, 9, 11, and 13 days respectively (left to right). The vertical bar represents the difference between the means using the kLSD ratio at $\mathrm{k}=100$. 

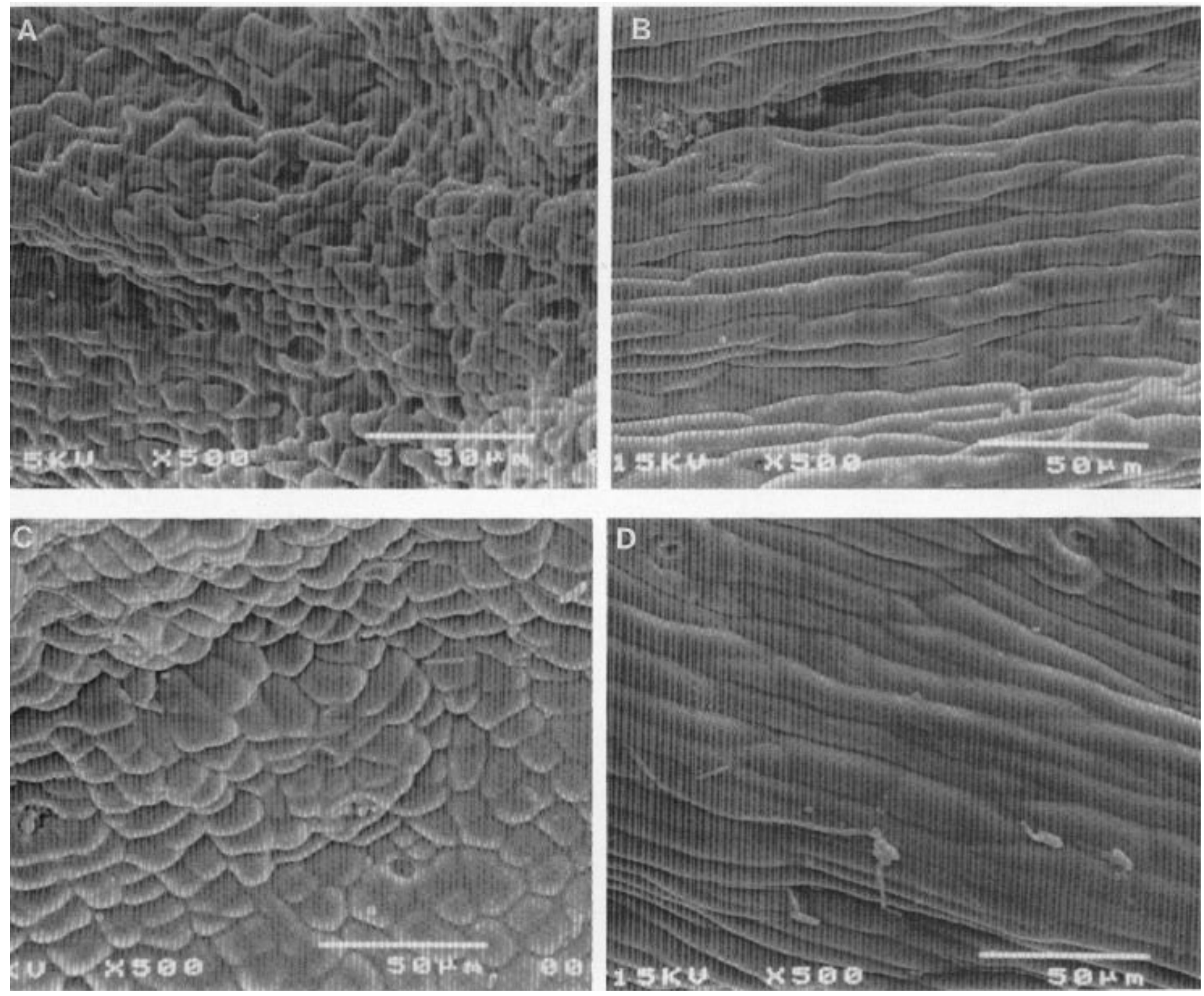

Fig. 4. Scanning electron micrographs (SEMs) of the pericarp surface after 13 days storage. Note the cracks (c) in the surface. (A) $60 \%$ Relative humidity (RH), base of spintern; (B) 60\% RH, midway along the spintern; (C) 95\% RH, base of spintern; (D) 95\% RH, midway along the spintern.

\section{Discussion}

Water is the major constituent of all fruit, and regulating its loss is a major requirement for maintaining postharvest quality for most fruit (Burton, 1982). The amount of weight loss that can be tolerated before a product becomes unsalable, ranges from as low as $3 \%$ for lettuce to as high as $37 \%$ for green beans (Burton, 1982). Rambutan fruit browning was unacceptable at weight losses $>25 \%$, depending on the storage $\mathrm{RH}$ and the duration of exposure (Fig. 1). Cultivar differences in the sensitivity to browning in terms of weight loss exist, with ' $\mathrm{R}-156$ ' being more sensitive to weight loss than ' $\mathrm{R}-134$ '. It is important to note that large fruit possess a smaller surface-to-volume ratio than small fruit and, hence, lose less moisture per unit fruit weight per unit time (Woods, 1990). Fruit shape also affects the ratio of surface area to volume, shrivelling occurring faster where there is a greater surface area per unit volume (Ben-Yehoshua, 1987). Obviously, the surface-tovolume ratio of rambutan fruit is greatly enhanced by the presence of spinterns (Landrigan et al., 1994). In the first season, fruit of the red cultivar were smaller, had longer spinterns, and a greater spintern density per unit surface area (unpublished data) than those of the yellow cultivar. Consequently, greater weight loss by the red cultivar occurred with concomitant increase in skin browning scores compared to fruit of the yellow cultivar. The more apparent skin browning on the red fruit than the yellow may also be due to pigmentation differences between the two cultivars. The loss of red pigmentation may contribute to more obvious browning in the red cultivar, while this is not the case on the skin in the yellow cultivar. The fact that the spinterns of both cultivars brown similarly may be due to pigment similarities and desiccation rates. The tips of the spinterns of both cultivars are usually green.

There was a storage time $\times \mathrm{RH}$ interaction in the development of fruit pericarp browning. At the lower humidities, skin browning became commercially unacceptable earlier at about $35 \%$ weight loss, which occurred after 7 days of storage. Fruit stored at $90 \%$ RH reached the same level of browning at a much lower percentage weight loss of about $20 \%$ and took longer in days to develop this level of browning. This showed that percentage weight loss was not the only determinant of pericarp browning, rather, there is a storage time $\times$ weight loss interaction. 
Skin and spintern browning appeared to develop independently. Browning did not necessarily begin at the tip of the spintern and advance down to the skin, as previously suggested by Lam et al. (1987). There were some differences between skin and spintern browning under certain conditions. Where spinterns had been damaged at the base, for example, by bending, browning occurred there even if the spintern above was not brown.

O'Hare et al. (1994), examined two red cultivars and found the a* parameter of color to be best correlated with overall visual skin color. We confirmed that the $\mathrm{a}^{*}$ values provided a good correlation with both skin and spintern browning in longer-term storage experiments ( 7 days). In the shorter term ( $<7$ days), a* values were not as well correlated to either skin or spintern browning. This may have been because the $a^{*}$ value is a measure of skin and spintern browning and, while browning of the spinterns was high in the shorter time periods, levels in the skin were low, with the two different components confounding the accuracy of the a* value reading.

As browning increased total phenol levels decreased, suggesting that the polymerization of phenols contributed to browning. The development of browning pigments correlated well with a decline in phenol concentration in other fruit (Macheix et al., 1990) and reflects the oxidation of phenolic compounds.

Surface morphology, as revealed by SEM, provided visual evidence of what happens during the development of water stress in these fruit. As weight loss increased, epidermal cells became severely shrivelled and cracks appeared in the wax layer. This was more pronounced earlier at lower RH levels. The skin showed more severe cracking than spinterns. It has also been found in the grape berry that disruption of the wax on the fruit surface greatly increases water loss rate (Ben-Yehoshua, 1987); whereas, for lychee, the development of microcracking occurred as a consequence of moisture loss (Underhill and Simons, 1993). It is likely that the cracking of the waxy cuticle on the surface of rambutan fruit further facilitated the loss of water and, hence, accelerated browning rate and loss of commercial acceptability.

Water is lost in rambutan fruit via the spinterns and replaced by water from the skin because of the presence of a continuous vascular system (Landrigan et al., 1994). Lychee is another fruit in which the pericarp desiccated preferentially (Underhill and Simons, 1993). They found that after $48 \mathrm{~h}$ at $25^{\circ} \mathrm{C}$ and $60 \% \mathrm{RH}$, the whole fruit lost $10 \%$ in weight and the pericarp lost $55 \%$, with no loss from the flesh. These authors referred to this as selective dehydration, with little movement of water between aril and pericarp. The structure of rambutan would appear to function in a similar manner. The phenomenon of water's being lost from the peel rather than the pulp had also been reported for oranges (BenYehoshua, 1987).

Water loss precedes browning and, over time, is correlated with browning. The physiological mechanisms associated with in- creased rambutan pericarp browning are clear, but the biochemical basis for the formation of browning pigments in rambutan still requires elucidation.

\section{Literature cited}

Ben-Yehoshua, S. 1987. Transpiration, water stress, and gas exchange, p. 113-70. In: J. Weichmann (ed.). Postharvest physiology of vegetables. Marcel Dekker, New York.

Burton, W.G. 1982. Postharvest physiology of food crops. Longman Scientific and Technical, Harlow, U.K.

Forbes-Smith, M.R., S.C. Morris, and K.J. Scott. 1989. An inexpensive and accurate humidity generating system. Lab. Practice 38:99-100, 103.

Hung, Y. 1990. Effect of curvature and surface area on colorimeter readings-A model study. J. Food Quality 13:259-269.

Lam, P.F., S. Kosiyachinda, M.C.C. Lizada, D.B. Mendoza, Jr., S. Prabawati, and S.K. Lee. 1987. Postharvest physiology and storage of rambutan, p. 39-50. In: P.F. Lam and S. Kosiyachinda (eds.). Rambutan: Fruit development, postharvest physiology and marketing in ASEAN. ASEAN Foodhandling Bur., Malaysia.

Landrigan, M., V. Sarafis, S.C. Morris, and W.B. McGlasson. 1994. Structural aspects of rambutan fruits and their relation to postharvest browning. J. Hort. Sci. 69:571-579.

Macheix, J., A. Fleuriet, and J. Billot. 1990. Fruit phenolics, CRC Press, Boca Raton, Fla.

Mendoza, Jr., D.B., E.R.B. Pantastico, and F.B. Javier. 1972. Storage and handling of rambutan (Nephelium lappaceum L.). Philippine Agr. 55:322-332.

O'Hare, T.J., A. Prasad, and A.W. Cooke. 1994. Low temperature and controlled atmosphere storage of rambutan. Postharvest Biol. Technol. 4:147-157.

Pantastico, E.B., J.B. Pantastico, and V.B. Cosico. 1975. Some forms and functions of the fruit and vegetable epidermis. Philippine J. Biol. 4:175197.

Rathjen, A.H. and S.P. Robinson. 1992. Characterisation of a variegated grapevine mutant showing reduced polyphenol oxidase activity. Austral. J. Plant Physiol. 19:43-54.

Singleton, V.L. and J.A. Rossi, Jr. 1965. Colorimetry of total phenolics with phosphomolybdic-phosphotungstic acid reagents. Amer. J. Enol. Viticult. 16:144-158.

Steel, R.G.D. and J.H. Torrie. 1980. Principles and procedures of statistics. McGraw-Hill, New York. p. 172-191.

Underhill, S.J.R. and D.H. Simons. 1993. Lychee (Litchi chinensis Sonn.) pericarp desiccation and the importance of postharvest micro-cracking. Scientia Hort. 54:287-294.

Weast, R.C., M.J. Astle, and W.H. Beyer (eds.). 1983. CRC handbook of chemistry and physics, 64th ed. CRC Press, Boca Raton, Fla. p. E-42. Wells, I. and J. Bagshaw. 1989. Handling rambutans after harvest. Queensland Fruit Veg. News. Feb:16-17.

Williams, M.H., M. Vesk, and M.G. Mullins. 1987. Tissue preparation for scanning electron microscopy of fruit surfaces: Comparison of fresh and cryopreserved specimens and replicas of banana peel. Micron Microsopica Acta. 18:27-31.

Woods, J.L. 1990. Moisture loss from fruit and vegetables. Postharvest News Info. 1:195-199. 